\title{
EL RECURSO PREVIO DE INCONSTITUCIONALIDAD CONTRA PROYECTOS DE LEY ORGANICA
}

\author{
POR \\ MANUEL ALBA NAVARRO \\ Letrado de las Cortes Generales
}

\begin{abstract}
SUMARIO
I. VALORACIÓN GENERAL DEL RECURSO PREVIO DE INCONSTITUCIONALIDAD. II. EI PROCESO DE PRODUCCIÓN NORMATTVA.-III. LA ARTICULACIÓN DEL ARTículo 79 LOTC EN EL PROCESO DE PRODUCCIÓN LEgISLATIVA: 1. Momento procedimental de intervención del Tribunal Constitucional; 2. Efectos del recurso: A) Consecuencias de la interposición del recurso; B) Consecuencias del pronunciamiento: a) Caso de apreciación de la constitucionalidad del proyecto; b). Caso de apreciación de inconstitucionalidad; c) La carencia de valor de cosa juzgada del pronunciamiento.-IV. ConcLusiones.
\end{abstract}

\section{VALORACION GENERAL DEL RECURSO PREVIO DE INCONSTITUCIONALIDAD}

Sucede muchas veces en el transcurso de la vida que los actos que se ejecutan sin la debida previsión originan más problemas con el paso del tiempo que los que se intenta resolver. No se trata simplemente de que la vida sea mucho más rica en su plural acontecer que la limitada capacidad de previsión de los seres humanos; esto es algo inevitable $\mathrm{y}$, por tanto, insoslayable. Se trata, por el contrario, de que instituciones, relaciones o normas jurídicas creadas en un momento de poca reflexión no sólo comportan los propios problemas que de la institución en sí misma se derivan, sino también suscitan el más complejo tema del adecuado engarce con el resto de la estructura o sistema donde se insertan.

Pues bien, algo parecido es lo que sucede con el recurso previo de inconstitucionalidad contra proyectos de Estatutos de Autonomía y de Leyes Orgánicas regulado por el capítulo II del título VI (Del control previo de inconstitucionalidad) de la Ley Orgánica 2/1979, de 3 de octubre, del Tribunal Constitucional.

En efecto, la aparición de dicha modalidad previa de fiscalización de la constitucionalidad no estaba expresamente contemplada en nuestra Constitu- 
ción ${ }^{1}$. Obviamente, nuestro texto fundamental partía de la base - $-\mathrm{y}$ así se demuestra tanto en los artículos 87 y siguientes, referidos a la elaboración de las leyes, como en los preceptos del título IX, dedicado al Tribunal Constitucional - de la modalidad o sistema del recurso de constitucionalidad a posteriori ${ }^{2}$ o sobre normas ya perfectas ${ }^{3}$.

Ello no quiere decir, a nuestro juicio, que se pueda hablar de una inconstitucionalidad radical de los artículos $2, e$ ), y 79 de la LOTC. Lo que sucede es que nuestra Constitución, en vez de optar por un camino de numerus clausus en la delimitación de las competencias del Tribunal Constitucional, introdujo una cláusula genérica en el apartado d) del artículo 161, según el cual el Tribunal es competente para conocer: d) De las demás materias que le atribuyan la Constitución o "las leyes orgánicas» ${ }^{4}$. Por esta vía se abrió la espita para que no sólo otras leyes orgánicas, sino en primer lugar su propia ley rectora, atribuyera al Tribunal Constitucional competencias no asignadas $a b$ initio por la Carta Magna ${ }^{5}$.

La extensión del sistema de recurso previo de inconstitucionalidad, previsto en el artículo 95.2 de la Constitución para los tratados internacionales, a otros ámbitos normativos como los antes señalados plantea, sin lugar a dudas, muchos más problemas que los que viene a solucionar. La cuestión de su constitucionalidad, se diga lo que se diga, no parece hoy día que pueda

\footnotetext{
${ }^{1}$ Así se puso de relieve, por ejemplo, tanto en las discusiones parlamentarias, intervenciones del portavoz de Minotía Catalana señor Roca Junyent (D. S. Congreso de los Diputados, día 23 de julio de 1979, B. O.C., pág. 1201); del señor Peces-Barba, representante del Grupo Socialista (ibíd., págs. 1211 y sigs), y del señor Solé Tura (ibíd., pág. 1217), como en la propia doctrina al analizar el texto; en este sentido véase Almagro Nosete en su Justicia constitucional (Madrid, 1980), cuando dice en la pág. 29 que ... la LOTC «amplia» el control previo de inconstitucionalidad a los proyectos de estatutos de autonomía y leyes orgánicas.

${ }_{2}$ Es significativo a este respecto que tres padres de la Constitución, Roca Junyent, Peces-Barba y Solé Tura, indicaran que esta modalidad de control previo no había estado presente en la mente del constituyente; lo cual, por otra parte, parece corroborarse, como posteriormente veremos, por la propia dicción de los pertinentes artículos de la Constitución.

${ }^{3}$ Para una exposición sintética de los diversos modelos o sistemas de control de la constitucionalidad pueden verse, entre otros, los siguientes trabajos publicados en la obra colectiva que sobre el Tribunal Constitucional publicó el Instituto de Estudios Fiscales como resultado de las Jornadas de Estudio que sobre aquel órgano constitucional organizó la Dirección General de lo. Contencioso del Estado: Javier Pérez Royo, La regulación de algunos aspectos del recurso de inconstitucionalidad: su influencia sobre la naturaleza del Tribunal Constitucional español en la Constitución española de 1978, páginas 2190 y sigs.; Alessandro Pizzorusso, Las sentencias «manipulativas» del Tribunal Constitucional italiano, págs. 279 y sigs., y J. J. González Rivas, La justicia constitucional. Los Tribunales Constitucionales en Europa Occidental, págs. 1243 y sigs.

4 Peces-Barba, en su trabajo El Tribunal Constitucional, incluido en la obra colectiva anteriormente citada, señalaba certeramente que probablemente bubiera sido más seguro plantear el tema de las competencias como «numerus clausus», aunque a continuación precisa que sin duda razones de prudencia y el temor a dejar temas no contemplados cuya inclusión bubiera exigido una reforma de la Constitución movieron a esta problemática solución. Véase ob. cit., pág. 2053.

${ }^{5}$ Esta cláusula abierta del artículo $161.1, d$ ), de la Constitución fue precisamente el punto básico de defensa de la tesis de la compatibilidad y constitucionalidad del recurso previo de inconstitucionalidad. Véase a este respecto la intervención de Alzaga Villaamil en el Diario de Sesiones del Congreso de los Diputados de 23 de julio de 1979, págs. 1217 y sigs.
} 
ya ponerse en tela de juicio, por lo menos en lo que a su regularidad formal atañe. No en vano no sólo no se impugnó en debido tiempo y forma la propia constitucionalidad de la LOTC, sino que, lo que es más significativo, fue iniciativa del propio Grupo Socialista del Congreso la de remitir la Ley Orgánica de Armonización del Proceso Autonómico al Tribunal Constitucional en virtud del procedimiento establecido en los artículos 79 y concordantes de la LOTC, aun cuando, claro está, no fuese el Grupo Socialista quien plantease el recurso.

Dicho lo cual, no hay que pensar que por el mero hecho de que una norma sea formalmente constitucional ésta se autojustifique en todos los efectos y consecuencias que lleva implícitos. Antes bien, los preceptos jurídicos son susceptibles de analizarse mediante parámetros muy variados, siendo la constitucionalidad uno de ellos. Muy otro es el juicio que'se pueda hacer del recurso previo de inconstitucionalidad si lo analizamos desde la óptica de los efectos políticos y jurídicos que produce.

Partiendo del nivel político-constitucional general, señalaba acertadamente Cascajo Castro ${ }^{6}$ el estado de tensión institucional existente entre las instancias legislativas y el Tribunal Constitucional. Cierto que hoy día el principio de separación de poderes como dogma no encuentra fácil acomodo en la doctrina constitucional, pero no es menos cierto que todavía se pueden distinguir en el ámbito de las competencias respectivas de los órganos constitucionales unas competencias genuinas o primarias de cada uno de ellos y otras accesorias o secundarias que se imputan al correspondiente poder en función del cumplimiento de otras tareas más relevantes ${ }^{7}$. Igualmente podríamos hablar de una serie de competencias ínsitas o inescindibles de cada uno de los órganos constitucionales y otra relación de facultades que entrarían en un ámbito que cabría denominar friccional en la medida en que cabe una convergencia o superposición de los poderes constitucionales legítimamente establecidos a la hora de actuar sus correspondientes competencias.

Pues bien, sin necesidad de entrar ahora en un análisis pormenorizado de lo que supone la aparición de los Tribunales Constitucionales para el dogma de la soberanía parlamentaria ${ }^{8}$, sí que parece lógico señalar que la mayor parte de las afirmaciones que se han producido al respecto del recurso previo de inconstitucionalidad hacen referencia al peligro de politización del Tribunal Constitucional, tema de permanente actualidad en la doctrina ${ }^{9}$. Aunque

- Véase J. Luis Cascajo Castro, Aproximación del tema de las funciones del Tribuñal Constitucional, en la obra colectiva antes citada, págs. 639-640.

7 Una exposición más detallada de esta tesis puede verse en mi trabajo sobre Las facultades de iniciativa, propuesta e informe en materia legislativa del Consejo General del Poder Judicial, publicado en el núm. 97, de la RAP.

${ }_{8}$ Véase sobre este tema el trabajo de Pablo Lucas Murillo de la Cueva La constitucionalidad de las leyes y la soberanía parlamentaria, en el núm. 7 (nueva época) de la Revista de Estudios Políticos.

9 Así, verbigracia, Roca Junyent, en su intervención antes citada, señalaba que en lo que se está pensando es en que el Tribunal Constitucional pueda salvar papeletas politicas, decisiones políticas que, a veces, no se tendrá el coraje de enfrentar en el nivel estrictamente político. Entonces, convertimos al Tribunal por esta vía en una «segunda instancia política...»; del :mismo peligro advertía agudamente el señor Pons Irazaźabal previendo la posibilidad y la tentación de ... convertir al Tribunal en un instrumento del Gobierno para canalizar la actuación parlamentaria... El diputado comunista señor. Solé Tura llegaba 
tras su paso por el Senado el texto del originario proyecto de ley quedó pulido y perfeccionado, el temor de que por esta vía se endosaran al Tribunal Constitucional temas de hondo contenido político que sobrepasen la natural dosis de politicidad de los asuntos sometidos a la Corte constitucional, no parece haberse desvanecido, sino, antes bien, reafirmado con la utilización práctica de esta vía.

Desde un punto de vista más técnico-jurídico, ha criticado la doctrina la implantación del recurso previo de inconstitucionalidad. Así, por ejemplo, González Pérez, tras justificar las censuras emitidas hacia esta fórmula, indica que su introducción se hace ... desnaturalizando los principios procesales y creando una figura de control previo anómala ${ }^{10}$. Para este autor, la carencia de fundamento de este recurso se debe a que los tribunales no están concebidos para decidir «a priori» acerca de la supuesta inconstitucionalidad de un proyecto normativo, interrumpiendo con su intervención el procedimiento legislativo ${ }^{11}$.

Aun cuando, como tendremos ocasión de ver después, estas objeciones fueron tenidas en cuenta por los parlamentarios, lo cierto es que el recurso previo de inconstitucionalidad suscita, prima facie, e independientemente de la valoración de su utilidad político-normativa-constitucional, más problemas de los que resuelve. Y ello no se debe sólo, aunque también, a la propia naturaleza en sí del recurso, sino sobre todo, al menos en lo que a la legislación española afecta, a la falta de previsión o de ensamblaje de la intervención de los diferentes órganos constitucionales en la elaboración de las leyes.

\section{EL PROCESO DE PRODUCCION NORMATIVA}

El ordenamiento jurídico, como estructura normativa, cuyos elementos básicos y esenciales son preceptos jurídicos, exige para adquirir tal categoría sistemática de ordenamiento determinar a quién está atribuida la facultad de producir o emanar normas, y también fijar cuándo dichas normas son válidas y perfectas y se insertan en el ordenamiento jurídico vigente y cuándo determinados preceptos dejan de tener vigencia y desaparecen del marco normativo.

La teoría general del Derecho ha elaborado el concepto de producción normativa para hacer referencia precisamente al cómo se han de emanar las normas. Dicho proceso de producción normativa aparece regulado por normas que no se dirigen de un modo frontal a regular las conductas de los ciudadanos, sino a determinar qué formalidades o vías deben de cumplimentar los órganos que tienen atribuidas potestades normativas. De estas normas, que Hart ha denominado acertadamente reglas de reconocimiento, en la medida

todavía a más y afirmaba que ... introducimos otra instancia, el Tribunal Constitucional, «al cual estamos otorgando derecbo de veto sobre la actividad legislativa del Congreso...». $\mathrm{La}$ confrontación de todas estas intervenciones puede hacerse en el Diario de Sesiones del día 23 de julio de 1979.

${ }_{10}$ Véase J. González Pérez, Derecbo Procesal Constitucional, Ed. Civitas, Madrid, 1980 , pág. 269.

"Op. cit., pág. 250. 
en que nos ayudan a conocer cuándo una norma forma parte de la estructura jurídica ${ }^{12}$, una parte esencial son aquellas destinadas a delimitar cómo se han de producir las leyes. No en vano han sido las leyes las normas jurídicas por excelencia. Como además resulta que la potestad legislativa es - junto con el poder presupuestario la competencia par excellence del Parlamento ${ }^{13}$, no es extraño que el procedimiento legislativo sea siempre una de las materias más minuciosamente regulada por las cartas fundamentales de los diversos países.

En nuestra Constitución son básicamente los artículos 87 a 91 los que fijan el procedimiento a seguir para emanar una ley. No quiere decir que sean los únicos preceptos a tener en cuenta, porque no sólo habrá que tener presentes otros requisitos circunstanciales (verbigracia, los previstos en el artículo 81.2 para las leyes orgánicas), sino también, y fundamentalmente, los preceptos reglamentarios que tanto en el Congreso de los Diputados como en el Senado desarrollan y detallan las líneas maestras trabadas en la Constitución.

De un análisis sistemático de este conglomerado normativo en sus distintas escalas caben señalar tres fases fundamentales en el proceso de producción normativa:

a) La iniciativa legislativa, que desencadena y pone en marcha todo el aparato productor de leyes ${ }^{14}$, y que los artículos 87,88 y 89 regulan en sus diversas modalidades.

b) El procedimiento legislativo «sensu stricto» o puramente intracameral, que es toda la fase que media entre la presentación de la iniciativa y la aprobación definitiva del texto del proyecto de ley ${ }^{15}$.

c) La tercera fase de sanción, promulgación y publicación, prevista en el artículo 91 de nuestro texto fundamental, respecto del cual el mejor análisis que se ha hecho en nuestro país corresponde, sin duda alguna, a Santamaría Pastor ${ }^{16}$.

Este proceso de producción legislativa se denomina también por un amplio sector de la doctrina procedimiento legislativo. No hay inconveniente en homologar este término con el de producción normativa siempre y cuando se tengan presentes las diversas fases del mismo.

Cuando hemos separado en sus diversas fases o instancias el iter de producción normativa no lo hemos hecho, ciertamente, por un prurito de atomización erudita o de un modo gratuito. Antes bien, queremos dejar claro desde este momento que una norma para obligar a todos, ciudadanos y poderes públicos (art. 9.1 de la Constitución), debe de reunir los requisitos esenciales

12 Véase H. L. A. Hart, The Concept of Law, Clarendon Press, Oxford, 1979.

${ }^{13}$ Verbigracia, art. 66.2 de la Constitución.

${ }^{14}$ Véase a este respecto la definición, válida aunque incompleta, que proporciona J. A. Santamaría Pastor en su comentario al art. 87 en la obra colectiva de Fernando Garrido y otros Comentarios a la Constitución, Ed. Civitas, Madrid, 1980, pág. 883. Igualmente es de inexcusable cita la brillante tesis doctoral recientemente presentada por J. F. Merino Merchán sobre La iniciativa de ley parlamentaria, aún inédita.

15 Para una teoría general del procedimiento legislativo puede consultarse la obra de S. Galeotti Contributo alla teoria del procedimento legislativo, Giuffrè, Milán, 1957.

${ }_{16}$ Véase op. cit., págs. 912 y sigs. En este agudo y penetrante comentario se demuestran los equívocos, disfunciones y problemas a los que podría llevar una aplicación stricto sensu del desafortunado precepto. 
de validez y eficacia. Y debe de reunirlos todos. Esta es la diferencia entre un proyecto de ley, aun cuando haya recorrido todas las instancias que median hasta la aprobación definitiva de las Cámaras, y una ley, que, además, ha cumplimentado la tercera fase que antes señalábamos como contenida en el artículo 91 de la Constitución y lo previsto en el artículo 2 del Código civil ${ }^{17}$.

De todas maneras, el que haya fases diversas no quiere decir que se puedan desligar entre sí las diversas instancias. Como subrayó en los debates parlamentarios Peces-Barba: Se ba dividido el procedimiento en diversos trámites. Abora bien, no es una materia distinta el trámite de una ley en estado de proyecto que el de una ley en estado de norma válida, sino que son «diversos momentos» en el proceso de producción normativa ${ }^{18}$.

Este proceso de producción normativa se hallaba perfectamente engarzado en nuestra Constitución de modo y manera que, a priori, y salvo pequeños problemas ya solucionados en gran parte ${ }^{19}$, la creación de leyes no suscitaba grandes temas.

\section{LA ARTICULACION DEL ARTIICULO 79 LOTC EN EL PROCESO DE PRODUCCION LEGISLATIVA}

Los problemas comienzan cuando se introduce, por mor de los artículos 2,e), y 79 de la Ley Orgánica del Tribunal Constitucional un procedimiento de control previo de la constitucionalidad no ya de leyes perfectas, válidas y vigentes, sino de «proyectos» de Estatutos de Autonomía y de leyes orgánicas.

Tenemos que manifestar, desde luego, nuestra absoluta discrepancia tanto con la instauración de este recurso en abstracto como, sobre todo, con la imperfección e incorrección de su confusa redacción, que no sólo plantea numerosas dudas de interpretación, sino que además abre la espita a nuevos métodos obstruccionistas en el Derecho parlamentario. Trataré a lo largo de estas líneas de poner de relieve el por qué de mi discrepancia.

\section{Momento procedimental de intervención del Tribunal Constitucional}

En primer término hay que fijar con nitidez el momento procedimental en que se produce la intervención del Tribunal Constitucional en este recurso previo de inconstitucionalidad. La supuesta ambigüedad del texto del proyecto de ley originario, aprobado en el Congreso, según el cual la interposi-

${ }^{17}$ Como dijo acertadamente Alzaga durante la discusión parlamentaria, ... evidentemente un proyecto normativo tiene naturaleza jurídica y alcance distinto de una ley o una disposición normativa propiamente dicha; es materia diversa... D. S. cit., págs. 1217 y siguientes.

${ }^{18}$ Ibíd., pág. 1222.

19 Así, por ejemplo, las dudas interpretativas que suscitaba el art. 89.2 de la Constitución, hoy resueltas por la dicción del art. 125 del Reglamento del Congreso. 
ción del mismo ... una vez establecido su «texto definitivo» $y$ antes de que el mismo sea sometido al siguiente trámite procedimental se intentó salvar por el Senado con una redacción que es la actualmente recogida en el artículo 79.1, según el cual el objeto de la impugnación es:

El texto definitivo del proyecto de ley orgánica tras su tramitación en ambas Cámaras y una vez que el Congreso se baya pronunciado, en su caso, sobre las enmiendas propuestas por el Senado.

De esta manera se intentaron conseguir dos tipos de objetivos. De una parte delimitar claramente el momento procedimental de interposición del recurso, que tiene un plazo de tres dias desde que el texto definitivo del proyecto recurrible estuviere concluido (art. 79.2 LOTC). De otro lado, se quería evitar la acusación de injerencia en las tareas parlamentarias de un órgano no legislativo como es el Tribunal Constitucional ${ }^{20}$. e indirectamente el Gobierno, legitimado para presentar este recurso previo de inconstitucionalidad.

La primera de las finalidades se logró, sin duda. Parece absolutamente claro, en función del artículo 79 LOTC, el momento de interposición del recurso. No queremos, no obstante, dejar de pasar la oportunidad de mostrar la antinomia que existe entre este artículo y el 91 de la Constitución. Mientras que en el primero de los preceptos se habla, correctamente, a mi juicio, de proyecto de ley orgánica, no deja de ser sorprendente que al mismo objeto normativo lo llame la Constitución, al menos en un momento, ley. En efecto, según el artículo 91 de la Constitución: El Rey sancionará, en el plazo de quince dias, «las leyes» aprobadas por las Cortes Generales, y las promulgará y ordenará su inmediata publicación. Debe considerarse, sin embargo, que lo que hay es una discordancia semántica dentro de la propia Constitución. No hay, de hecho, posibilidad de diferenciar objetivamente esto que el artículo 91 llama leyes y lo que dice el artículo 90.2 cuando manifiesta que... «el proyecto» no podrá ser sometido al Rey para sanción... No debe, pues, achacarse la confusión a la LOTC, sino a la impropiedad terminológica de la propia Constitución al atribuir dos conceptos -interrelacionados pero separables, como veíamos antes- a un mismo objeto.

La finalidad de querer evitar la injerencia de órganos no legislativos en el procedimiento legislativo no se logra, sin embargo, plenamente. Digamos que a las fases normales de producción normativa se une una nueva de pendencia del proyecto de ley definitivamente aprobado por las Cámaras. Durante esta fase de incertidumbre (corta pero cierta) queda a disponibilidad de los legitimados para interponer el recurso previo de inconstitucionalidad ${ }^{21}$,

${ }^{20}$ Sobre este punto, en el que habían recaído críticas, puede verse la explicación del senador Calatayud Maldonado en el Diario de Sesiones del Senado de 3 de septiembre de 1979, pág. 471, cuando decía que al señalarse este momento procedimental de interposición del recurso, ... la interferencia del Gobierno en la soberania de las Cámaras es nula, puesto que las Cámaras ya ban agotado por su propia via y antes de que se produzcan estos efectos es cuando únicamente puede interponerse el recurso constitucional previo. El mismo senador hacía una analogía de este recurso con el principio de firmeza de los actos administrativos en el contencioso, que veremos luego que es inexacta.

${ }^{21}$ Cfr. art. 79.2 . 
la decisión de permitir que el proyecto siga o no su marcha. Pero con esto nos estamos adentrando ya en el tema de los efectos que produce este recurso, que deben de ser objeto de estudio en un nuevo apartado.

\section{Efectos del recurso}

Una vez fijado el momento en que se puede incitar la actuación del Tribunal Constitucional, parece llegada la hora de analizar los efectos que de este recurso previo de inconstitucionalidad se desprenden. Para lo cual creemos conveniente distinguir dos categorías genéricas de consecuencias: las derivadas de la mera interposición del recurso y las que se desprenden del eventual pronunciamiento que recaiga en el proceso.

\section{A) Consecuencias de la interposición del recurso}

Respecto del primer apartado, ha sido el propio Pleno del Tribunal Constitucional el que mediante acuerdo de 14 de julio de 1982 (BOE de 19 de julio de 1982), por el que aprueba normas para la tramitación de los recursos previos de inconstitucionalidad, ha señalado que a la interposición se anuda un efecto de tanta trascendencia como es el «dejar en suspenso el plazo para la sanción real, previsto en el artículo 91 de la Constitución».

Esto responde tanto a la solución dada al momento de inserción procedimental del Tribunal en el proceso de producción normativa como a ser una consecuencia concreta del precepto contenido en el último inciso del apartado 2 del artículo 79, según el cual:

La interposición del recurso suspenderá automáticamente la tramitación del proyecto y el transcurso de los plazos.

Efecto suspensivo que recuerda, por su parte, el apartado 2 del artículo 2 del Acuerdo del Pleno del Tribunal Constitucional antes citado.

De esta manera, el recurso previo de inconstitucionalidad escapa a la regla general válida para los recursos y cuestiones de constitucionalidad, que, recogida en el artículo 30 LOTC, señala que la admisión (nótese que no se refiere a la mera interposición, sino a la admisión) de los mismos «no suspenderá» la vigencia ni la aplicación de la ley, de la disposición normativa o del acto con fuerza de ley, "excepto» en el caso en que el Gobierno se ampare en lo dispuesto por el artículo 161.2 de la Constitución...

Así, el régimen de consecuencias inmediatas de la interposición del recurso previo es el más contundente, el más trenchant de los previstos en la Ley Orgánica del Tribunal Constitucional, y esto debido a que en el procedimiento entablado, en base al artículo 161.2 de la Constitución, se prevé, cuando menos, un plazo máximo de cinco meses en el que el Tribunal Constitucional deberá ratificar o levantar la suspensión aneja a la impugnación.

Ciertamente que la propia naturaleza del recurso previo de inconstitucionalidad exigía per se un efecto de este tipo que produjese ex officio la detención de la tramitación ordinaria del proceso de producción normativa. Pero 
no deja de ser paradójico que los efectos que se pretenden conseguir con la instauración de este recurso pueden ser distorsionados sin mayor dificultad. En efecto, el propio Parlamento, al aprobar este artículo 79 , ha introducido uno de los mejores y más fáciles medios de hacer obstruccionismo parlamentario. En la medida en que la legitimación exigible para presentar este tipo de proceso o recurso no es excesivamente severa ${ }^{22}$, no cabe la más mínima duda sobre la facilitación que se hace por mor del artículo 79.2 LOTC del empleo de medios obstruccionistas por minorías no muy amplias (un séptimo de la Cámara en el caso del Congreso de los Diputados).

Si esto es así in genere, cuánto más no lo será al final de cada legislatura. En los últimos meses de las mismas bastará a la minoría que espere el cambio de vientos y votos con presentar o interponer sistemáticamente el recurso previo de inconstitucionalidad a los proyectos de ley orgánica que haya aprobado la mayoría prevista en el artículo 81.2 de la Constitución. De esta manera se asegura dicha minoría la congelación de la aprobación y publicación definitiva de los mismos, quedando a la expectativa de lo que pueda suceder en los nuevos comicios. Que este procedimiento se emplee o no es cuestión que dependerá de la sensatez y ponderación de las fuerzas parlamentarias, pero que el sistema instaurado por la. LOTC se presta a ello es algo sobre lo que no cabe el más mínimo resquicio de duda. Todo ello independientemente de lo que diremos más tarde sobre un eventual pronunciamiento de inconstitucionalidad total o parcial del proyecto en cuestión.

\section{B) Consecuencias del pronunciamiento}

Hasta ahora hemos abordado los efectos que emanan de la mera interposición del recurso previo de inconstitucionalidad. Nos toca ahora entrar en el análisis de las consecuencias que produce el pronunciamiento ${ }^{23}$ del Tribunal en un recurso de este tipo. Tres diversos puntos de enfoque admite, a nuestro juicio, este apartado. El primero es el supuesto en el que el Tribunal Constitucional declara la conformidad con la Constitución del proyecto impugnado. El segundo está marcado por la eventualidad de un pronunciamien-

22 Véase la valoración que antes de la aprobación de la LOTC hacían Sergio Galeotti y Bruno Rossi en su trabajo El Tribunal Constitucional en la nueva Constitución española: medios. de impugnación y legitimados para actuar, publicado en el núm. 7 de la $\mathrm{REP}$, dedicado a las garantías constitucionales, especialmente en las páginas 127 y 140 y siguientes. En la medida en que la legitimación prevista en el art. 79.2 no sufre alteraciones al hacerse per relationem, estamos de acuerdo con dichos autores cuando afirman la generosidad del ordenamiento constitucional español en punto al tema de la legitimación.

${ }^{23}$ De pronunciamiento y no de sentencia habla la LOTC, queriendo marcar unas diferencias que realmente no son tales, ya que, como dice González Pérez con toda exactitud, pese a su inclusión en el título dedicado a la regulación del "control previo de inconstitucionalidad» y a que se prescinde del término de «sentencia» para designar a la decisión del Tribunal, es un "proceso". Así lo pone de manifiesto la calificación de "recurso" (que en la incorrecta terminología de la ley equivale a proceso) y la sumisión al régimen general del proceso de inconstitucionalidad. Cfr. Derecbo Procesal Constitucional, cit., pág. 249. En sentido coincidente se pronunciaba ya en los debates parlamentarios PecesBarba cuando sostenía que ... si analizamos el artículo 79 del proyecto (...) veremos que es un «auténtico recurso de inconstitucionalidad», que tiene sus efectos... Véase Diario de Sesiones, cit., pág. 1213. 
to declarativo de algún tipo de inconstitucionalidad. Por último, habrá que estudiar el significado del desafortunadísimo apartado 5 del artículo 79 LOTC, referente a los efectos de un pronunciamiento en vía previa sobre eventuales recursos ulteriores ya en vía sucesiva.

\section{a) Caso de apreciación de la constitucionalidad del proyecto.}

Sin duda es el supuesto más claro aquel en el que el Tribunal Constitucional declara la inexistencia de la inconstitucionalidad alegada, supuesto en el cual seguirá su curso el correspondiente procedimiento.

En este caso el pronunciamiento se comunicará a los que lo interpusieron, a aquellos otros órganos constitucionales interesados $\mathrm{y}$, sobre todo, se pondrá en conocimiento de la Presidencia del Gobierno, que lo someterá al Rey para la sanción y ordenación de publicación, pasando a ser una ley más. Respecto del pronunciamiento del Tribunal, creemos que, debido a la analogía que antes señalábamos con las sentencias, deberá ser también publicado en el $B O E$ en cumplimiento de lo preceptuado en los artículos 164.1 de la Constitución y 86.2 de la LOTC. Igualmente creemos posible la formulación de votos particulares por parte de los magistrados discrepantes.

\section{b) Caso de apreciación de inconstitucionalidad.}

Muchos más problemas suscita el hallazgo por el Tribunal Constitucional de inconstitucionalidad en algunos o todos los preceptos del proyecto de ley orgánica recurrido.

El primer efecto, parece claro, es que se impida que siga la tramitación normal del proyecto de ley ${ }^{24}$. Esta no podrá continuar hasta que tales preceptos (los tildados de anticonstitucionalidad) bayan sido suprimidos o modificados por el órgano competente $[(79.4, b)]$. Difícilmente se podía haber redactado un precepto tan oscuro, ambiguo y que derive tantos problemas de interpretación y de sentido común como éste que acabamos de transcribir.

En primer término, parece que lo que cacofónicamente llama la LOTC órgano competente no son sino las Cortes Generales, las cuales tienen atribuida la potestad legislativa y son, por ende, el órgano constitucional que puede suprimir o modificar preceptos de un proyecto de ley. De esta forma, parece que tenemos ya pergeñado un segundo y nada despreciable efecto derivado del pronunciamiento del Tribunal: éste reabre el procedimiento legislativo "stricto sensu» al que nos referíamos antes ${ }^{25}$. Del Tribunal Constitucional depende, por consiguiente, el dar por terminada la tarea de las Cámaras o hacer que éstas tengan que trabajar de nuevo sobre los principios que la propia Corte fija.

${ }^{24}$... lo que se procura es una declaración de inconstitucionalidad que comporta el que el precepto no pueda llegar basta el final, no puede ser aprobado, no puede ser publicado, no puede tener vigencia...; cfr. Martín Toval, Diario de Sesiones, cit., pág. 1215.

${ }^{25}$ Queda, pues, en entredicho la afirmación del senador Calatayud sobre el agotamiento de la vía propia de las Cámaras y parece, por contra, confirmarse la tesis antes mencionada de Solé Tura, quien, con un fino sentido constitucionalista, hablaba de «dere cho de veto» del Tribunal Constitucional sobre la actividad legislativa de las Cámaras. 
Pero esta reapertura de la labor normativa del Parlamento plantea toda una cascada de interrogantes que a veces no tienen una respuesta unívoca.

En primer término, y de acuerdo con el valor obstruccionista que antes atribuíamos al recurso previo de inconstitucionalidad, hay que retomar todo el procedimiento legislativo. Así, tendrá que discutir el Congreso la nueva formulación normativa de esos artículos o decidir su supresión definitiva, trasladar su texto al Senado, que lo estudiará de nuevo; vuelta al Congreso, en caso de que se hayan introducido modificaciones, y decisión definitiva, esta vez sí, de la Cámara Baja. Parece obvio que en todo este proceso pasará un tiempo bastante apreciable para aquellos que no quieran ver la ley perfecta. A todo esto, nada impide - salvo la lógica, el sentido común y la decisión sobre admisión a trámite que consagra el apartado $1 \mathrm{del}$ artículo $4 .^{\circ}$ del Acuerdo del Tribunal Constitucional antes citado, de 14 de julio de 1982la reproducción de otro recurso previo de inconstitucionalidad sobre el nuevo proyecto reformulado por las Cámaras ${ }^{26}$.

Empero, si la decisión del Tribunal Constitucional reabre el procedimiento legislativo en su plenitud, cabe preguntarse si este pronunciamiento acota o no el ámbito de los retoques parlamentarios. O dicho de otro modo: ¿puede el Gobierno retirar el proyecto de ley? ¿Es susceptible dicho proyecto de modificaciones que no sean las estrictamente previstas por el Tribunal Constitucional?

Respecto a la primera de las preguntas se puede afirmar que ambos $R e-$ glamentos, el del Congreso y el del Senado, contienen normas sustancialmente idénticas. Tanto el artículo 128 del Reglamento del Congreso como el 127 del Senado facultan al Gobierno para retirar los proyectos de ley en cualquier instante anterior a la aprobación final de cada Cámara ${ }^{27}$. Parece prima facie que la aprobación final de las Cámaras es anterior a la interposición del recurso ${ }^{28}$, pero también es lícito suponer que el pronunciamiento del Tribunal ha convertido aquella decisión final en decisión no firme. No en vano las Cámaras van a tener que pronunciarse de nuevo y emitir otras decisiones finales. Si sólo hubiera una decisión final, la consecuencia lógica sería que el proyecto de ley pasaría a ser ley sin los artículos modificados o suprimidos por el Tribunal Constitucional. En la medida en que el órgano competente es el que tiene que volver a pronunciarse sobre los mismos, no es descabellado pensar que existe la posibilidad para el Gobierno de retirar el proyecto de ley.

Esto, que en principio podría parecer un disparate, pensamos que no es tal. Supongamos que el proyecto viene del Tribunal Constitucional descabezado en sus artículos claves, en el arco de bóveda, en la trama que lo justificaba. ¿No es más lógica la solución de una retirada digna del proyecto, una vez apreciada la inconstitucionalidad de sus puntos fundamentales, que

${ }^{26}$ Todo ello sin que, como tendremos oportunidad de ver después, el pronunciamiento del Tribunal Constitucional prejuzgue la decisión en ulteriores recursos. ¡Todo un modelo de economía procesal!

27 Aprovechemos la ocasión para recalcar que la LOTC admite literalmente la interposición del recurso previo de inconstitucionalidad únicamente para los proyectos de ley orgánica y no para las proposiciones. Debe entenderse que es un mero lapsus y que también éstas pueden estar afectadas por esta vía procesal.

${ }^{28}$ Cfr. art. 79.1 y 2 LOTC. 
el mantenimiento a machamartillo de un texto políticamente inocuo o no querido, e incluso jurídicamente deforme? Amén de que, como luego veremos, no está claro el aspecto del ulterior procedimiento legislativo parlamentario aplicable al texto retornado del Tribunal. Sin afirmar contundentemente la virtualidad jurídica de una retirada del proyecto por parte del Ejecutivo, queremos simplemente constatar que esta posibilidad no carece de base jurídica ni política.

Dicho lo cual pienso que esta posibilidad es también aplicable cuando se ha producido un cambio en el Gobierno. No meramente un cambio de personas, sino, más todavía, una mutación de las fuerzas políticas gobernantes ${ }^{29}$.

Además, junto a la retirada formal del proyecto tildado de anticonstitucionalidad, queda otra posibilidad tan práctica como real: la congelación del susodicho proyecto. De la dicción del artículo $79.4, b$ ), se desprende que lo que el Tribunal Constitucional levanta con su pronunciamiento es un obstáculo o veto a la continuación de la tramitación, sin que los preceptos incursos en contradicción con la Constitución sean suprimidos o modificados. Nada obliga, sin embargo, a que las Cámaras tengan que tramitar el proyecto reformándolo de acuerdo con los dictados contenidos en el pronunciamiento. Bastaría en este caso al legislativo con arrinconar fácticamente el proyecto $\mathrm{y}$ dejarlo dormir en el sueño de los justos ${ }^{30}$.

Pasemos ahora al supuesto de que existe una voluntad auténtica de reformular el proyecto de acuerdo con lo contenido en el pronunciamiento del Tribunal Constitucional. Dos aspectos distintos hay que diferenciar en este caso. En primer término, los artículos a los que afecta, a juicio del Tribunal Constitucional, la inconstitucionalidad. En segundo lugar, aquellos preceptos que se ajusten a la legalidad constitucional.

Respecto de la primera hipótesis aún habría que diferenciar entre el pronunciamiento del Tribunal determinando la necesidad de suprimir determinadas disposiciones del proyecto, en cuyo caso el máximo juzgador constitucional ejerce lo que Kelsen definió como legislación negativa, y el juicio del Tribunal señalando las modificaciones que deben sufrir algunos artículos del proyecto $\mathrm{y}$, además, el sentido de las mismas.

En este último caso ha hablado la doctrina italiana, con indudable acierto,

${ }^{29}$ Este es el caso que se produciría ante una hipotética decisión del Tribunal Constitucional pronunciándose en favor de la inconstitucionalidad de determinados preceptos de la LOAPA. En este caso, el proyecto de ley, que habría pasado bibernado el periodo interlegislaturas y al que, por ende, no le afectaría lo previsto por el art. 207 del Reglamento del Congreso de los Diputados y por la disposición adicional primera del Reglamento del Senado, se encontraría en su retorno a las Cámaras con un Gobierno que no fue el que formuló la iniciativa. El sentido común parece admitir también la posibilidad de que el nuevo Gobierno no se vea obligatoriamente compelido a tramitar un proyecto heredado y en el cual puede no tener mayores intereses. Una decisión en sentido contrario afectaría al principio de manos libres del nuevo Gobierno al inicio de la legislatura que han consagrado las disposiciones anteriormente mencionadas.

${ }_{30}$ Pensemos, por ejemplo, en el supuesto de que el Tribunal Constitucional dictamine que la LOAPA no puede tener carácter de ley orgánica, que es uno de los principales motivos de impugnación de este proyecto. Desvirtuado en sus posibles efectos frente a los diversos Estatutos de Autonomía, podría convenir a los grupos que lo sostuvieron el dejar el tema olvidado, sin los hipotéticos efectos negativos de cara a la opinión pública que significaría la retirada formal del proyecto. 
de sentencias-delegación ${ }^{31}$. Esta acepción se debe a que presenta analogías con una ley de delegación, de las previstas en nuestro ordenamiento constitucional en el artículo 82. Así como en éstas las Cortes Generales emiten una ley de bases fijando los principios y criterios que debe de seguir el Gobierno al elaborar el texto del decreto legislativo, en el pronunciamiento del Tribunal Constitucional es obvio que se incluirán los criterios que deben de cumplimentarse en la reformulación de los artículos que deben de modificarse. Así ha funcionado el sistema en Italia ${ }^{32}$ y suponemos que, de hecho, así funcionará en España ${ }^{33}$.

Junto con los artículos tachados de inconstitucionalidad en su formulación originaria existirán también preceptos cuya redacción sea constitucionalmente aceptable. ¿Qué sucede con los mismos? En un principio hay que descartar para este supuesto la aplicación analógica del artículo 164.2 de la Constitución ${ }^{34}$. Aquí no puede hablarse en ningún momento de que subsista la vigencia de una ley, por el mero hecho, antes apuntado, de que no se ha llegado a aprobar una norma válida, perfecta y, por ende, vigente.

Por ello pensamos que dichos preceptos deben de seguir la suerte general que siga el proyecto en su nueva andadura parlamentaria. Podrán, por tanto, ser enmendados, alterados e incluso suprimidos. No sólo el pronunciamiento del Tribunal Constitucional declarándolos -explícita o implícitamente- constitucionales no obliga a mantenerlos tal cual, sino que, además, la exigencia lógica de que el proyecto sea un totum único, un cuerpo vertebrado, puede exigir su modificación o supresión en función de los principios informadores del proyecto ${ }^{35}$.

Dicho lo cual, no queremos cerrar el tema sin hacer referencia a determinados preceptos de la LOTC que pueden amparar resoluciones del Tribunal que aclaren puntos oscuros. Al realizarse este trabajo antes de que se haya producido nunca un pronunciamiento en un recurso de este tipo, estamos tratando únicamente de exponer y dar opiniones respecto de los problemas que este tipo de vía jurídica ocasiona. Sin embargo, está claro que el Tribunal Constitucional puede tener otra idea acerca del cumplimiento que

${ }^{31}$ Cfr. el anterior artículo de A. Pizzorusso en sus págs. 293-294.

32 Véase, respecto de los principales problemas derivados de las genéricamente llamadas sentencias manipulativas, la sucinta pero brillante exposición de Pizzorusso en el artículo antes citado, págs. 294-296.

${ }^{33}$ Nótese que en este caso no se puede hablar ya del Tribunal Constitucional como legislador negativo, sino, antes bien, como legislador positivo o colegislador, puesto que no se limita a prevenir o eliminar del ordenamiento eventuales disposiciones inconstitucionales, sino que determina, señalándolo, cuál debe de ser el contenido de las normas que los sustituyan.

${ }^{34} \mathrm{La}$ contradicción del tenor de este artículo con el esquema del recurso previo de inconstitucionalidad ya fue apuntado en su momento agudamente por Peces-Barba al hacer una enumeración de los datos jurídico-constitucionales que se oponían a la introducción de dicho recurso. Cfr. Diario de Sesiones cit., pág. 1212.

${ }_{35}$ Así, verbigracia, se puede ver en las decisiones del Consejo Constitucional francés las explícitas referencias a la separabilidad e inseparabilidad de los artículos de un proyecto, puesto que, no lo olvidemos, el control del Consejo Constitucional es -como en el caso que nos ocupa- preventivo o previo. Cfr. Resolución de 16 de enero de 1982 sobre el proyecto de ley de nacionalización, en el BJC núm. 10, de febrero de 1982, y la Decisión núm. 82-137 del mismo constitucional de 25 de febrero de 1982 sobre el proyecto de ley de descentralización, recogida en el BJC núm. 14, de junio de 1982. 
de su pronunciamiento debe hacerse. A este respecto no podemos olvidar que, de una parte, el artículo 92 LOTC admite que el Tribunal, bien en el pronunciamiento, bien en actos posteriores, resuelva las incidencias de la ejecución, que son precisamente las que tratamos de plantear ahora, con una labor más que nada de prospectiva jurídica. Por otro lado, el artículo 93.1 de la misma LOTC faculta a las partes obligadas al cumplimiento de las sentencias a solicitar en el plazo de dos días desde su notificación la aclaración de las mismas. Pensamos, sin embargo, que en el caso que nos ocupa deben de ser los propios órganos rectores de las Cámaras - los presidentes y las mesas - quienes decidan todos y cada uno de los temas de Derecho parlamentario conducentes al correcto cumplimiento del pronunciamiento del Tribunal Constitucional en un recurso previo de esta índole.

\section{c) La carencia de valor de cosa juzgada del pronunciamiento.}

Hemos tenido ocasión a lo largo del presente trabajo de manifestar nuestra opinión contraria al recurso previo de inconstitucionalidad, tanto in abstracto como en su concreta regulación positiva. Podría, sin embargo, admitirse que de este recurso se desprendiesen efectos benéficos ${ }^{36}$. Hay, empero, un precepto que anula, a primera vista, los hipotéticos beneficios del mismo. Me refiero, claro está, al desafortunadísimo apartado 5 del tantas veces mencionado artículo 79 LOTC ${ }^{37}$.

González Pérez ha intentado explicar la perplejidad que produce este precepto señalando que, a su juicio, sólo podrá ponerse en juego cuando en el recurso previo el pronunciamiento ha sido favorable a la constitucionalidad de la norma impugnada ${ }^{38}$. Pienso que no existen datos positivos que avalen suficientemente esta interpretación.

Los errores que supone la estridencia de que se pueda hacer un doble proceso a los mismos preceptos se deriva de la inmadurez e imprevisión que reinaron entre aquellos que defendieron la instauración de este recurso previo. En efecto, podría sustentarse con cierta lógica que el recurso previo era valioso si su relación con el proceso de inconstitucionalidad contra Estatutos de Autonomía y Leyes Orgánicas fuese de exclusividad y no de acumulación. $\mathrm{O}$ lo que es lo mismo, lo que ha demostrado su constitucionalidad una vez no tiene que hacer constantemente prueba de su conformidad con la Carta Fundamental ${ }^{39}$. Lo que sucede es que debido a que el proceso de inconstitucionalidad que se plasma en la Constitución es el recurso a posteriori o

${ }^{36}$ En este sentido afirmaba Alzaga que ... en ciertas ocasiones la medicina preventiva es muy superior en eficacia y en economía de costes bumanos a la medicina quirúrgica. Cfr. Diario de Sesiones cit., pág. 1220. También decía el senador Villar Arregui que ... es mejor que una eventual ley orgánica inconstitucional no se aplique nunca a que esa ley orgánica produzca efectos generadores de situaciones a veces irreversibles. Véase Diario de Sesiones cit., pág. 477.

${ }_{37}$ Según el cual: El pronunciamiento en el recurso previo no prejuzga la decisión del Tribunal en los recursos que pudieren interponerse tras la entrada en vigor con fuerza de ley del texto impugnado en la vía previa.

${ }_{33}$ Cfr. esta interpretación en la nota a pie de página núm. 6, en la pág. 245 de su Derecbo procesal..., cit.

${ }^{39}$ Excluimos, claro está, el procedimiento previsto por el artículo 55.2 LOTC. 
sucesivo y éste no podía ser en modo alguno eliminado so pena de ser tachada la LOTC de inconstitucional, lo que se hizo fue añadir el recurso previo al recurso de inconstitucionalidad sensu stricto, sin darse cuenta de las disfunciones que ello implicaba ${ }^{40}$. Con lo cual tenemos un doble proceso al mismo objeto.

La negación del valor de cosa juzgada al pronunciamiento emitido en el recurso previo de inconstitucionalidad es uno de los principales defectos (por si tuviera pocos) de este mecanismo procesal. De esto dio cuenta el magistrado constitucional Jerónimo Arozamena, quien, debido al sentido práctico que le otorgaba su experiencia judicial, se manifestaba preocupado por esta disfuncionalidad ${ }^{41}$. Creo que su afirmación en el sentido de que un examen previo coincidente en objeto y fundamento con un proceso posterior no puede resolverse negando efecto alguno a pronunciamiento previo en el recurso posterior. Es cierto, efectivamente, que hay que buscar otras interpretaciones posibles que faciliten la coordinación e incidencia de dos actuaciones del Tribunal sobre el mismo objeto. Caso contrario, el obstruccionismo al que antes nos referíamos habrá encontrado su auténtico filón ${ }^{42}$.

\section{CONCLUSIONES}

De todo lo anteriormente tratado se revela, ante todo, que la constitucionalidad formal de una norma no asegura ni su utilidad práctica ni la coherencia con el resto del ordenamiento donde se inserta. Si algo se desprende sin ningún género de dudas de esta modesta reflexión es la falta de ensamblaje de esta institución procesal constitucional en el totum del circuito constitucional. En gran parte la imprevisión y el deseo de dar cauce jurídicoformal a eventos que no se produjeron luego en la realidad fueron los polvos que amenazan con traer unos lodos que hay que creer que no fueron deliberadamente queridos: lentitud procesal, obstruccionismo parlamentario, agobio de trabajo innecesario para el Tribunal Constitucional, etc.

De otra parte, hemos visto cómo la instauración de este recurso hace del Tribunal Constitucional un auténtico colegislador, se quiera o no. $Y$ no ya en calidad de legislador negativo, sino aún más, de emisor de sentenciasdelegación que habrá de desarrollar el Parlamento. Frente a esto pienso que hay que potenciar al máximo la autonomía parlamentaria a la hora de fijar el iter procedimental de un proyecto reenviado a las mismas por el Tribunal Constitucional. Las Cortes no están en modo alguno obligadas a re-presentar el proyecto y pueden bien congelarlo, bien hacerlo desaparecer definitivamente mediante la retirada del mismo por parte del Gobierno.

${ }^{40}$ Esta explicación de que no había inconstitucionalidad del recurso previo porque no se elimina el proceso de inconstitucionalidad es la que late, en el fondo, en las intervenciones antes citadas de Alzaga.

${ }^{41}$ Véanse sus reflexiones en el artículo El recurso de inconstitucionalidad en la obra colectiva antes citada, págs. 149-150.

${ }_{42}$ No dejamos, sin embargo, de reconocer las dificultades que entraña la dicción literal del art. 79.5 LOTC. 
Por último, parece sensato pedir un esfuerzo hermenéutico de la jurisprudencia constitucional que dote de sentido a una norma, como es el artículo 79.5 LOTC, cuyas virtualidades son a todas luces disfuncionales. Lo contrario llevaría a una esquizofrenia en la tarea juzgadora del propio Tribunal, que tendría que olvidarse completamente de lo que él mismo dijo con anterioridad respecto de idénticas normas. 